\title{
Study on Storage Stability of Different Homemade Extruded Foods Products Prepared by Using Malted Composite Flour
}

Luxmi Gautam* and Alka Gupta

Department of Foods and Nutrition, Ethelind School of Home Science, SHUATS, Allahabad, Uttar Pradesh, India

\begin{abstract}
Study was conducted on Storage stability of homemade extruded food products prepared by using malted composite flour (malted wheat, chickpea, pearl mille, soybean and dehydrated Colocasia leaves powder). The products can be stored at room temperature up to 90 days in polythene bags. However, with lapse of storage period, a gradual increase in free fatty acids and peroxide value of all developed homemade extruded foods was noticed. But, the free fatty acids and peroxide value of developed food products were within permissible limits after 90th day of storage period. The study thus suggests that replacement of traditional food ingredients like rice flour, basen or refined wheat flour with composite malted flour for preparing various homemade extruded food products in the diet may be feasible and beneficial, too. Keeping in view the nutritional profile of malted composite flour the development of these products will not only diversify the uses of malted composite flour but also will be beneficial for human health.
\end{abstract}

Keywords: Storage stability; Homemade extruded food; Composite flour; Free fatty acid; Peroxide value; Moisture

\section{Introduction}

Among convenience foods, a major share of market belongs to the category of deep fried snacks. These are manufactured by organized sector as well as at smaller scale in cottage industries. The origin of most of these products can be traced to the traditional practices, wherein for want of better preservation techniques for fresh foods, fried foods naturally became a choice due to their shelf stability. The raw ingredients used for the deep-fried snacks are mostly cereals or legumes, or a combination of both and in certain cases vegetables like potato, cassava and raw banana are also used. Advances made in this sector by modern food processors include use of additives and packaging materials to increase shelf stability of products. The acceptability of a food product depends on the extent to which deterioration has occurred and oxidative rancidity is a major cause of food deterioration This in turn represents a major cause of loss of nutritional quality as well as cause of concern for food safety, as the oxidized fats in a very high dosage have been shown to have toxic effects [1]. Therefore, studies in which degradation of frying oils and analysis of rancidity volatiles are valuable in understanding the oil oxidation state and such products are the fried foods. Ready-To-Eat Snacks and Namkeen are generally considered as take away food and usually preferred as hunger quencher and are eaten whenever the consumers are hungry. The snack preparation is mainly composed of wheat flour, rice flour and enriched by gram flour. In India, the consumption of snacks food is increasing day by day. Size and shape are most important aspect for acceptability, convenience in use, and cognizance of provenance, decorative nature and so on, that they considered jointly. The packaging of food is one of the prime requisites to improve and monitor the producer to consumer food production system. It forms an integral part of manufacturing process providing the link between the processor and the consumer. In fact, it plays a dominant role in the total food manufacturing activity and in marketing sector. Snack food must be packed in attractive packaging so as to given impression of wholesomeness and freshness to increase sales appeal and it should be hygienic. With growing concern of diet, weight control and general health, government bodies are recommending to the peoples and making a conscious effort to eat healthier, natural snacks such as fruit, vegetable, nuts and cereal grains while avoiding highcalorie, low-calorie nutrient junk food. In light of above discussions, a study on the development of snack foods was undertaken from malted composite flour (wheat flour, chickpea flour, pearl millet flour, soybean and dehydrated colocasia leaves powder).

\section{Materials and Methods}

\section{Experimental site}

The present investigation was carry out in the Nutrition Research Laboratory, Foods and Nutrition, Ethelind School of Home Science.

\section{Procurement of raw materials}

Wheat, pearl millet, chickpea, soybean and Colocasia Leaves and other ingredient were purchased from local market of Allahabad district, for the preparation of composite flour.

\section{Processing of wheat, pearl millet, soybean and chickpea}

The soaking period ( 12 hours), germination temperature $\left(31^{\circ} \mathrm{C}\right)$ and germination period ( 48 hours) was opted for malting. The malted wheat, millet, chickpea, and soybean were Preliminary drying was done in air for 1-2 hrs. Final drying is done under sun to about $10 \%$ moisture. Vegetative parts were removed by rubbing and these foods were ground to powder and passed through the fine mesh sieve then storing in airtight container followed by Gautam et al. [2].

\section{Preparation of colocasia leaves powder}

The leaves were thoroughly washed in water 2-3 times to remove the dust and impurities. Healthy leaves will be sorted then steam blanched for 5 to $10 \mathrm{~min}$ in a pressure cooker without any chemical treatment. Then the leaves were dried at a temperature of 50 to $60^{\circ} \mathrm{C}$ for 12-15 hours till 6-7 percent moisture remains. The dried leaves were then turned to homogeneous powders passed through a fine mesh sieve and store in air-tight container.

\section{Preparation of composite flour}

The composite flours were obtained by the mixing of selected

*Corresponding author: Luxmi Gautam, Department of Foods and Nutrition, Ethelind School of Home Science, SHUATS, Allahabad, Uttar Pradesh, India, Tel: 917983015820; E-mail: laxmi_gautam93@yahoo.com

Received April 14, 2017; Accepted April 20, 2017; Published April 27, 2017

Citation: Gautam L, Gupta A (2017) Study on Storage Stability of Different Homemade Extruded Foods Products Prepared by Using Malted Composite Flour. Nat Prod Chem Res 5: 264. doi: 10.4172/2329-6836.1000264

Copyright: $\odot 2017$ Gautam L, et al. This is an open-access article distributed under the terms of the Creative Commons Attribution License, which permits unrestricted use, distribution, and reproduction in any medium, provided the original author and source are credited. 
cereals, pulse, millets and green leafy vegetables such as malted wheat flour (MWF), malted pearl millet flour (MPMF), malted soybean flour (MSF), malted chickpea flour (MCF) and dehydrated colocasia leaves powder (DCLP) in the different ratio i.e., (MWF-40\%, MPMF-20\%, MCF-20\%, MSF-10\%, DCLP 10\%).

\section{Development of value added extruded food products}

Value added extruded food products were made by using malted composite flour in different proportions. Namkeen sav, saviyan, chakli and kachari was prepared by the house hold extrusion process. Hence, recipes were selected and made according to the instruction given in the method. One sample served as controlled designated as standard $\left(\mathbf{T}_{\mathbf{0}}\right)$ and other test recipes i.e., $\mathbf{T}_{1}, \mathbf{T}_{2}$ and $\mathbf{T}_{3}$ were made by incorporation of processed composite flour ( $\mathrm{FWF}+\mathrm{MPMF}+\mathrm{MCF}+\mathrm{MSF}+\mathrm{DCLP})$ in different concentration of $\mathbf{3 5 \%} \mathbf{5 5 \%} \mathbf{7 5 \%}$ respectively. All recipes were prepared in food science lab SHIATS Allahabad.

\section{Shelf life of value added extruded products}

Namkeen save, chakli, seviyan and kachri were packed in polyethylene pouches and stored at room temperature. Storage stability of the products was assessed by determining moisture (AOAC 2005), Free fatty acids and Peroxide value of stored products at monthly interval which is $0,30,60$, and 90 days in the fat were determined by the standard method of AOAC (2000).

Free fatty acids are calculated by the formula:

$$
\text { Free fatty acid }(\%)=\frac{50 v \times N \times F \times 100}{W \times 1000}
$$

Where, $\mathrm{v}=$ Volume of $\mathrm{NaOH}$ required, $\mathrm{N}=$ Normality of $\mathrm{NaOH}$ solution, F=Equivalent weight (282) of FFA (oleic acid), W=Weight of sample
Peroxide value was calculated as:

Peroxide value (meq peroxide/1000 $\mathrm{g})=\frac{(S-B) \times N \times 1000}{\text { Weight of sample }}$

Where, $\mathrm{B}=$ Volume $(\mathrm{mL})$ of $\mathrm{Na}_{2} \mathrm{~S}_{2} \mathrm{O}_{3}$ used for titration of blank, $\mathrm{S}=$ Volume $(\mathrm{mL})$ of $\mathrm{Na}_{2} \mathrm{~S}_{2} \mathrm{O}_{3}$ used for titration of sample, $\mathrm{N}=$ Normality of $\mathrm{Na}_{2} \mathrm{~S}_{2} \mathrm{O}_{3}$ solution.

\section{Results and Discussion}

\section{Free fatty acid}

Table 1 shows that free fatty acid of Namkeen Sev varied from 144.18 to $261.15 \pm 0.21$ in the polyethylene bags for the Period of 3 months. The average mean values were $144.12 \pm 0.12 \%$ on 0 days, $180.12 \pm 0.08 \%$ on 30 days, $222.06 \pm 0.13 \%$, on 60 days, $261.15 \pm 0.21 \%$ on 90 days. In case of chakli the free fatty acid was slight increased from 0 days to 90 days. The mean values of free fatty acid of all treatment were increased slightly. Same level of free fatty acid increment was also found in Seviyan. These results in line with the [3] studied the free fatty acid in different pearl millet based food products and identified the peroxide value on the zero day of the storage were found to be as $4.65,4.97$ and $5.12 \mathrm{meq} / 1000 \mathrm{~g}$ fat, respectively for control, pearl millet supplemented Type-I and Type-II crispies. Control, pearl millet incorporated Type-I and Type-II had peroxide value ranged from 5.37 to 6.17 , with the highest for pearl millet based Type-II crispies and lowest was for the control crispies. After 60 day of storage the peroxide value increased significantly with the supplementation of pearl millet in crispies. Similarly, on the 90 day of storage the peroxide value increased up to two folds than that zero day of the storage.

\section{Peroxide value}

According to Table 2 Peroxide value of developed extruded food products were not exceed more than $7.4 \mathrm{meq} / 1000 \mathrm{~g}$. The mean values

\begin{tabular}{|c|c|c|c|c|}
\hline \multirow{2}{*}{$\begin{array}{c}\text { Products } \\
\text { Namkeen Sev }\end{array}$} & \multicolumn{4}{|c|}{ Storage period } \\
\hline & 0 day & 30 day & 60 day & 90 day \\
\hline $\begin{array}{c}\mathbf{T}_{0} \\
(\mathrm{~B}: 100 \%)\end{array}$ & $144.12 \pm 0.12$ & $180.12 \pm 0.08$ & $222.06 \pm 0.13$ & $261.15 \pm 0.21$ \\
\hline $\mathrm{T}_{1}$ (MCF: B: 35:65) & $161.12 \pm 1.26$ & $121.11 \pm 0.74$ & $241.71 \pm 0.59$ & $292.01 \pm 0.35$ \\
\hline $\mathrm{T}_{2}$ (MCF: B: 55:45) & $162.11 \pm 0.94$ & $123.01 \pm 0.15$ & $245.11 \pm 0.13$ & $292.73 \pm 0.44$ \\
\hline $\mathrm{T}_{3}$ (MCF: B: $\left.75: 25\right)$ & $164.01 \pm 0.86$ & $123.13 \pm 0.18$ & $246.03 \pm 0.19$ & $293.05 \pm 0.31$ \\
\hline \multicolumn{5}{|l|}{ Chakli } \\
\hline $\begin{array}{c}\mathrm{T}_{0} \\
\text { (R: B: 50:50) }\end{array}$ & $114.12 \pm 0.02$ & $140.12 \pm 0.06$ & $180.02 \pm 0.15$ & $230.05 \pm 0.31$ \\
\hline $\mathrm{T}_{1}$ (MCF: RB: $35: 65$ ) & $136.06 \pm 1.22$ & $161.11 \pm 0.64$ & $201.61 \pm 0.39$ & $250.01 \pm 0.33$ \\
\hline $\mathrm{T}_{2}$ (MCF: RB: 55:45) & $138.11 \pm 0.84$ & $161.03 \pm 0.12$ & $204.01 \pm 0.06$ & $254.33 \pm 0.24$ \\
\hline $\mathrm{T}_{3}$ (MCF: RB: $75: 25$ ) & $138.05 \pm 0.96$ & $163.12 \pm 0.15$ & $205.03 \pm 0.09$ & $256.01 \pm 0.21$ \\
\hline \multicolumn{5}{|l|}{ Seviyan } \\
\hline $\begin{array}{c}\mathbf{T}_{0} \\
\text { (RF:100\%) }\end{array}$ & $37.82 \pm 0.22$ & $63.90 \pm 0.09$ & $100.66 \pm 0.19$ & $125.55 \pm 0.08$ \\
\hline $\mathrm{T}_{1}$ (MCF: RF: 35:65) & $57.82 \pm 0.56$ & $86.31 \pm 0.12$ & $130.11 \pm 0.08$ & $169.72 \pm 0.25$ \\
\hline $\mathrm{T}_{2}$ (MCF: RF: 55:45) & $58.35 \pm 0.12$ & $85.99 \pm 0.05$ & $131.1 \pm 0.10$ & $170.33 \pm 0.24$ \\
\hline $\mathrm{T}_{3}$ (MCF: RF: 75:25) & $58.99 \pm 0.19$ & $85.44 \pm 0.17$ & $132.05 \pm 0.09$ & $172.05 \pm 0.34$ \\
\hline \multicolumn{5}{|l|}{ Kachri } \\
\hline $\begin{array}{c}\mathbf{T}_{0} \\
\text { (R:100\%) }\end{array}$ & $35.22 \pm 0.12$ & $59.70 \pm 0.09$ & $94.26 \pm 0.09$ & $119.05 \pm 0.18$ \\
\hline $\mathrm{T}_{1}$ (MCF: R: 35:65) & $52.12 \pm 0.16$ & $80.11 \pm 0.11$ & $121.41 \pm 0.06$ & $160.22 \pm 0.27$ \\
\hline $\mathrm{T}_{\mathbf{2}}$ (MCF: R: 55:45) & $52.35 \pm 0.14$ & $80.69 \pm 0.07$ & $123.1 \pm 0.09$ & $163.13 \pm 0.14$ \\
\hline $\mathrm{T}_{3}$ (MCF: R: 75:25) & $53.39 \pm 0.15$ & $80.34 \pm 0.15$ & $125.05 \pm 0.07$ & $165.15 \pm 0.24$ \\
\hline
\end{tabular}

Values are mean \pm SE of three independent determinations; MCF: malted composite flour; B: Basen; RB: Rice flour and Basen; RF: Refined wheat flour; R: Rice Table 1: Effect of storage period on free fatty acid $(\mathrm{mg} / 100 \mathrm{~g}$ fat, as oleic acid) content of malted composite flour homemade extruded products. 
Citation: Gautam L, Gupta A (2017) Study on Storage Stability of Different Homemade Extruded Foods Products Prepared by Using Malted Composite Flour. Nat Prod Chem Res 5: 264. doi: 10.4172/2329-6836.1000264

Page 3 of 4

\begin{tabular}{|c|c|c|c|c|}
\hline \multirow{3}{*}{ Storage period days } & \multicolumn{4}{|c|}{ Peroxide value (meq/1000 g fat) } \\
\hline & \multicolumn{4}{|c|}{ Namkeen Sev } \\
\hline & $T_{0}$ & $T_{1}$ & $T_{2}$ & $\mathbf{T}_{3}$ \\
\hline 0 & 5.37 & 4.65 & 5.01 & 6.05 \\
\hline 30 & 5.87 & 4.97 & 5.67 & 6.79 \\
\hline 60 & 6.01 & 5.12 & 5.52 & 7.02 \\
\hline \multirow[t]{3}{*}{90} & 6.84 & 5.63 & 6 & 7.4 \\
\hline & \multicolumn{4}{|c|}{ Chakli } \\
\hline & $\mathrm{T}_{0}$ & $T_{1}$ & $\mathrm{~T}_{2}$ & $\mathrm{~T}_{3}$ \\
\hline 0 & 4.01 & 4.71 & 5.01 & 5.36 \\
\hline 30 & 4.25 & 5.01 & 5.42 & 5.54 \\
\hline 60 & 5.46 & 5.48 & 5.87 & 6.01 \\
\hline \multirow[t]{3}{*}{90} & 5.89 & 5.99 & 6.01 & 6.45 \\
\hline & \multicolumn{4}{|c|}{ Seviyan } \\
\hline & $T_{0}$ & $\mathrm{~T}_{1}$ & $T_{2}$ & $\mathrm{~T}_{3}$ \\
\hline 0 & 0.86 & 2.32 & 2.47 & 2.71 \\
\hline 30 & 1.45 & 2.69 & 2.89 & 2.99 \\
\hline 60 & 1.75 & 2.74 & 3.12 & 3.18 \\
\hline \multirow[t]{3}{*}{90} & 2.01 & 2.89 & 3.55 & 3.64 \\
\hline & \multicolumn{4}{|c|}{ Kachri } \\
\hline & $T_{0}$ & $\mathrm{~T}_{1}$ & $T_{2}$ & $T_{3}$ \\
\hline 0 & 0.59 & 1.26 & 1.52 & 1.85 \\
\hline 30 & 0.86 & 1.48 & 1.77 & 2.05 \\
\hline 60 & 1.02 & 1.72 & 2.01 & 2.31 \\
\hline 90 & 1.41 & 1.99 & 2.25 & 2.68 \\
\hline
\end{tabular}

Table 2: Effect of storage period on peroxide value (meq/1000 $\mathrm{g}$ fat) of malted composite flour homemade extruded products.

\begin{tabular}{|c|c|c|c|c|}
\hline \multirow{3}{*}{ Days of Storage } & \multicolumn{4}{|c|}{ Moisture content $\%$} \\
\hline & \multicolumn{4}{|c|}{ Namkeen Sev } \\
\hline & $T_{0}$ & $T_{1}$ & $T_{2}$ & $\mathrm{~T}_{3}$ \\
\hline 0 & 2.02 & 2.06 & 2.24 & 2.58 \\
\hline 30 & 2.39 & 2.48 & 2.54 & 2.72 \\
\hline 60 & 2.68 & 2.96 & 3.02 & 3.33 \\
\hline \multirow[t]{3}{*}{90} & 3.05 & 3.29 & 3.34 & 3.59 \\
\hline & \multicolumn{4}{|c|}{ Chakli } \\
\hline & $T_{0}$ & $\mathrm{~T}_{1}$ & $\mathrm{~T}_{2}$ & $T_{3}$ \\
\hline 0 & 2.48 & 2.54 & 2.78 & 2.89 \\
\hline 30 & 2.69 & 2.75 & 2.98 & 3.01 \\
\hline 60 & 3.11 & 3.22 & 3.25 & 3.39 \\
\hline \multirow[t]{3}{*}{90} & 3.25 & 3.4 & 3.41 & 3.58 \\
\hline & \multicolumn{4}{|c|}{ Seviyan } \\
\hline & $T_{0}$ & $\mathrm{~T}_{1}$ & $\mathrm{~T}_{2}$ & $\mathrm{~T}_{3}$ \\
\hline 0 & 3.01 & 3.19 & 3.29 & 3.89 \\
\hline 30 & 3.21 & 3.54 & 3.65 & 4.09 \\
\hline 60 & 3.35 & 3.79 & 4 & 4.14 \\
\hline \multirow[t]{3}{*}{90} & 3.55 & 3.99 & 4.27 & 4.34 \\
\hline & \multicolumn{4}{|c|}{ Kachari } \\
\hline & $T_{0}$ & $\mathrm{~T}_{1}$ & $\mathrm{~T}_{2}$ & $\mathbf{T}_{3}$ \\
\hline 0 & 2.01 & 2.21 & 2.38 & 2.51 \\
\hline 30 & 2.25 & 2.35 & 2.46 & 2.71 \\
\hline 60 & 2.44 & 2.58 & 2.64 & 3.02 \\
\hline 90 & 2.87 & 3.01 & 3.15 & 3.29 \\
\hline
\end{tabular}

Table 3: Effect of storage period on moisture content of prepared homemade extruded food products.

of peroxide were ranged between 0.59 to 7.4 . The maximum value of peroxide is $20 \mathrm{meq} / 1000 \mathrm{~g}$. Developed products under this study were found very low peroxide value, so the developed food products can be successfully consumed at least for three months.
Similar study was done by Uma et al. prepared deep fat frying snack food and observe storage stability of developed snacks and founded that free fatty acid, and peroxide value of prepared snack food were ranged between $0.92 \mathrm{meq} / 1000 \mathrm{~g}$. 


\section{Moisture content}

Moisture content of all prepared homemade extruded food products i.e., Namkeen Sev was found to be 2.02 to 3.59, in chakli 2.48 to 3.58 , in seviyan 3.01 to 4.34 , and in kachri 2.01 to 3.29 percent from 0 days to 90 days. The increase in moisture content of all prepared food products Namkeen Sev, Chakli, Seviyan and kachri was slow during storage. This is may be due to that kachri is a dehydrated preserved extruded food product so the moisture content was very low and it can be successfully stored for a period of six months. It was also concluded that packaging material also affected the moisture content of snack food sample. Mamta [3] prepared different snack foods with the help of millets and other cereals and assess storage stability for a period of 90 days and observe moisture content of developed food products under the acceptable limit. Table 3 shows that a slight difference in moisture content was observed in all treatments from 0 days to 90 days.

\section{Conclusion}

Snack food samples based on malted composite flour were found that stored very easy at household like as control snack food sample. To conduct study on ambient storage behavior all four samples packed in high-density polyethylene and the increase in moisture content of all prepared food products Namkeen Sev, Chakli, Seviyan and kachri was slow during storage periods. The mean values of free fatty acid of all treatment were increased slightly and Peroxide value of developed extruded food products were not exceed more than $7.4 \mathrm{meq} / 1000 \mathrm{~g}$. Developed products under this study were found very low peroxide value, so the developed food products can be successfully consumed at least for three months. Thus, these snack food samples could be of great help in improving the health snack food peoples by serving as good supplements and provide a new way of consumption of such malted wheat, chickpea, pearl millet and soybean flour which cannot be consumed directly but has high nutritive value.

\section{References}

1. Sen S, Sen DP (1993) Oxidized fatty acid content of heat damaged frying oils and Indian deep fat fried products. JOTAI, pp: 89-91.

2. Gautam L, Chaturvedi N, Gupta A (2014) Development of micronutrients rich homemade extruded food products with the incorporation of processed foxtail millet, wheat and chickpea. IJCH 26: 288-293.

3. Mamta M (2010) Development and nutritional evaluation of pearl millet (Pennisetum glaucum) based convenience foods. CCSHAU, Hisar, India. 